\title{
Quality and patient experience: A six-dimensional approach for the future of healthcare
}

\author{
Wen-ta Chiu ${ }^{1,2}$, Rachele Hwong ${ }^{1}$, Jason Chiu ${ }^{1}$, Bill Huang ${ }^{1}$, JJ Stewart ${ }^{1}$, Tina T. Tsai*1 ${ }^{*}$, Su-yen Wu ${ }^{1}$, Spencer Liu ${ }^{1}$, \\ Nicole Chorvat ${ }^{1}$, Sasha $\mathrm{Yu}^{1}$, Jon Aquino ${ }^{1}$, Matthew Lin ${ }^{1}$, Jonathan $\mathrm{Wu}^{1}$ \\ ${ }^{1}$ AHMC Healthcare Inc., Alhambra, CA, USA \\ ${ }^{2}$ Taipei Medical University, Taipei, Taiwan
}

Received: January 13, 2016

Accepted: February 10, 2016

Online Published: March 2, 2016

DOI: $10.5430 /$ jha.v5n3p40

URL: http://dx.doi.org/10.5430/jha.v5n3p40

\begin{abstract}
The Affordable Care Act (ACA) has significantly altered the American healthcare system. Through the establishment of the ACA, Centers for Medicare and Medicaid Services (CMS) introduced Value-Based Purchasing (VBP), a pay-for-performance program, to the hospital payment system. From a community hospital's standpoint, a multifaceted approach to quality and patient satisfaction on better managing the health of the community was recognized: what begins in the community ends in the hospital as a valuable indicator for each individual's well-being. This article depicts the process of utilizing a six-dimensional approach on engaging stakeholders to improve quality of care and patient satisfaction: (1) inpatient, (2) emergency department, (3) employee, (4) physician relationships, (5) outpatient, and (6) community. As the effect of the ACA becomes more prominent, hospitals should maintain their organizational flow and care coordination through the six-dimensional approach to bring patients and their families back to the center of their care.
\end{abstract}

Key Words: Affordable care act, Value-based purchasing, Community hospital, Quality of care, Patient satisfaction

\section{INTRODUCTION}

The Affordable Care Act (ACA) has significantly altered the American healthcare system. The ACA has expanded healthcare access to millions of uninsured individuals, promoted patient-centered care with an emphasis on preventative care, and linked reimbursement to healthcare quality. ${ }^{[1]}$ Hospitals are particularly influenced by the paradigm shift in payment system from fee-for-service to pay-for-performance. ${ }^{[2]}$

Under the ACA, Congress authorized Centers for Medicare and Medicaid Services (CMS), the largest single-payer for hospital services, ${ }^{[3]}$ to introduce Value-Based Purchasing (VBP) to the hospital payment system. VBP is a standardized evaluation strategy to incentivize hospitals on improving quality of care and financial efficiency by withholding segments of CMS reimbursement. VBP is comprised of four different domains which include patient experience, clinical process, outcome, and efficiency of care. Hospitals are able to regain their reimbursement figures by meeting VBP measurements through safe and high quality care upon their patients. $^{[4]}$

Patient experience is a significant dimension of VBP. Studies have found strong linkage between patient satisfaction and quality indicators. As an example, higher patient satisfaction is correlated to better treatment adherence, outcomes, and medical information retention. ${ }^{[5-9]}$ As of 2016, patient experience accounts for $25 \%$ of the total VBP, and is measured

*Correspondence: Tina T. Tsai; Email: tina.tsai@ahmchealth.com; Address: AHMC Healthcare Inc., Alhambra, CA, USA. 
by the following areas in the Hospital Consumer Assessment of Healthcare Providers and Services survey (HCAHPS): (1) communication with nurses, (2) communication with doctors, (3) responsiveness of hospital staff, (4) hospital environment (cleanliness and quietness), (5) pain management, (6) communication regarding medications, (7) discharge information, (8) care transition, and (9) overall rating and willingness to recommend. ${ }^{[10]}$

As the healthcare industry continues to evolve under the ACA's influence, hospitals across the nation are actively researching effective strategies to further cultivate quality and delivery of care. From a community hospital's standpoint, a multifaceted approach to quality and patient satisfaction is recognized: what begins in the community will impact hospitals. This article depicts the process of utilizing a six-dimensional approach to improve quality of care and patient satisfaction (see Figure 1): (1) Inpatient, (2) Emergency Department (ED), (3) Employee, (4) Physician Relationship, (5)Outpatient, and (6) Community.

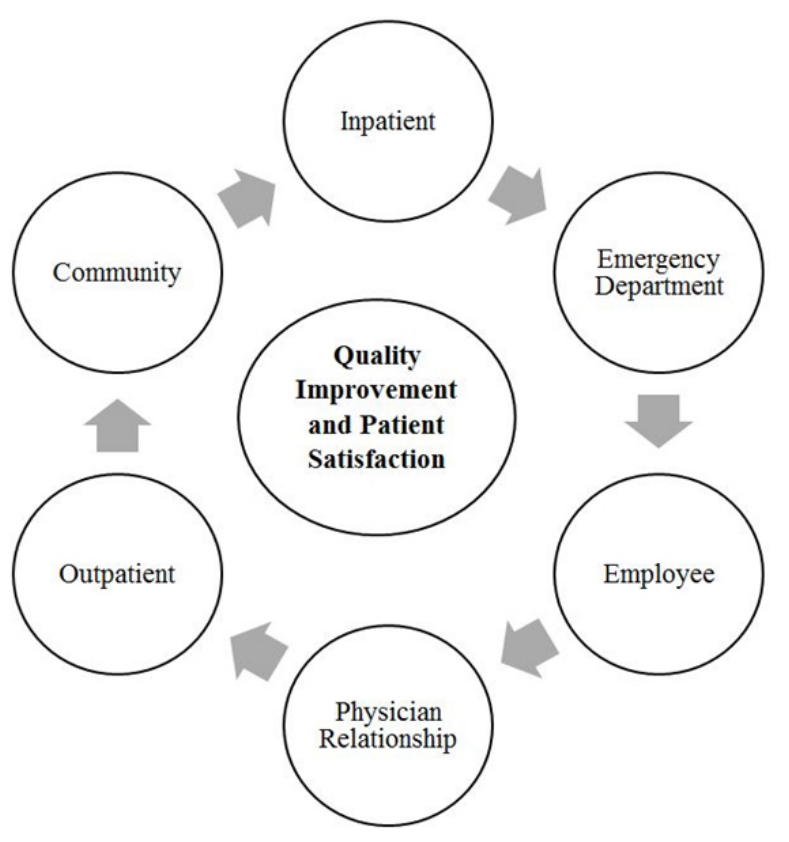

Figure 1. Six-dimensional approach to patient satisfaction and quality improvement

\section{MeTHODS}

\subsection{Settings}

AHMC Healthcare System (abbreviated as AHMC) currently consists of seven community hospitals in the Los Angeles County and Orange County of Southern California. The seven hospitals are Alhambra Hospital Medical Center, Anaheim Regional Medical Center, Garfield Medical Center,
Greater El Monte Community Hospital, Monterey Park Hospital, San Gabriel Valley Medical Center, and Whittier Hospital Medical Center. In 2016, Alhambra Hospital Medical Center was ranked in the Top 100 U.S. Hospitals by Truven Health Analytics. ${ }^{[1]}$ In 2013 and 2015, Garfield Medical Center, Greater El Monte Community Hospital, Monterey Park Hospital, and San Gabriel Valley Medical Center were awarded with Top Performer on Joint Commission Key Quality Measures. ${ }^{[12,13]}$ The system has a total of 1,246 beds, 2,662 affiliated physicians, and 5,776 employees. AHMC facilities are open hospitals where physicians and mid-level providers are not employed by the hospital, but are granted privilege to send and treat their patients. Our hospitals receive more than 170,000 ED visits on an annual basis.

Inpatient and ED patient experience are currently measured by HCAHPS and Emergency Department Patient Experience with Care (EDPEC) surveys. While EDPEC is currently not mandated by CMS, AHMC hospitals admit a high number of patients from the ED, and therefore, EDPEC is considered as an integral component of patient experience.

AHMC Healthcare System partners with J.L. Morgan and Associates, a third-party CMS-approved vendor, to administer HCAHPS and ED patient satisfaction through telephone surveys after patient discharge. J.L. Morgan and Associates randomly survey a subset of patients on a voluntary basis. If the patient is unavailable, six more follow-up attempts would be made. Both surveys exclude patients with psychiatric conditions. Survey questions have Likert-type responses ranging from 1 (never or strongly disagree) to 4 (always or strongly agree). Top box score indicates the percentage of participants who responded 4 in the questions.

\subsection{Inpatient}

Inpatient experience is an essential factor as it measures the quality of care from a patient's perspective. Patients who are admitted to hospitals have higher acuity symptoms which require attentive and compassionate care from skilled hospital caregivers. Inpatient satisfaction is measured by HCAHPS. ${ }^{[14]}$ System-wide HCAHPS top box aggregate data from 2010 to 2016 were included in the report (see Figure 2).

Within the past six years, AHMC's HCAHPS top box score has gradually improved to reach the statewide (California) average benchmark in patient experience. After reviewing HCAHPS results and following up with patients, AHMC implemented multiple patient-focused initiatives which further encouraged hospitals towards consistent progress since 2013. AHMC staff were trained in communication tools, such as AIDET (Acknowledge, Introduction, Duration, Explanation, 
Thank You), to enable them on consistent communication with patients about their treatment processes, changes, and delays. AHMC facilities also strongly support hiring multilingual staff to accommodate the culturally diverse communities in Southern California. Patient advocates and nurses proactively address patients' and their families' needs by visiting patient rooms and performing basic care tasks on a consistent basis, also known as patient rounding. ${ }^{[15,16]}$ Studies have found patient rounding as an influential strategy to not only foster patient satisfaction but to also reduce hospital- related conditions and injuries (falls, bed ulcers, etc.), and frequent usage of call lights. ${ }^{[15-17]}$ AHMC hospital administrative teams and directors utilize leadership rounding and huddles to ensure consistency in performance while recognizing and sharing feedback from patients with staff. Other hospital-wide initiatives such as designated quiet time and hospital environmental services rounding have been implemented to address patients' comfort and safety. Support and commitment from hospital leadership is necessary to develop sustaining results from these initiatives. ${ }^{[16]}$

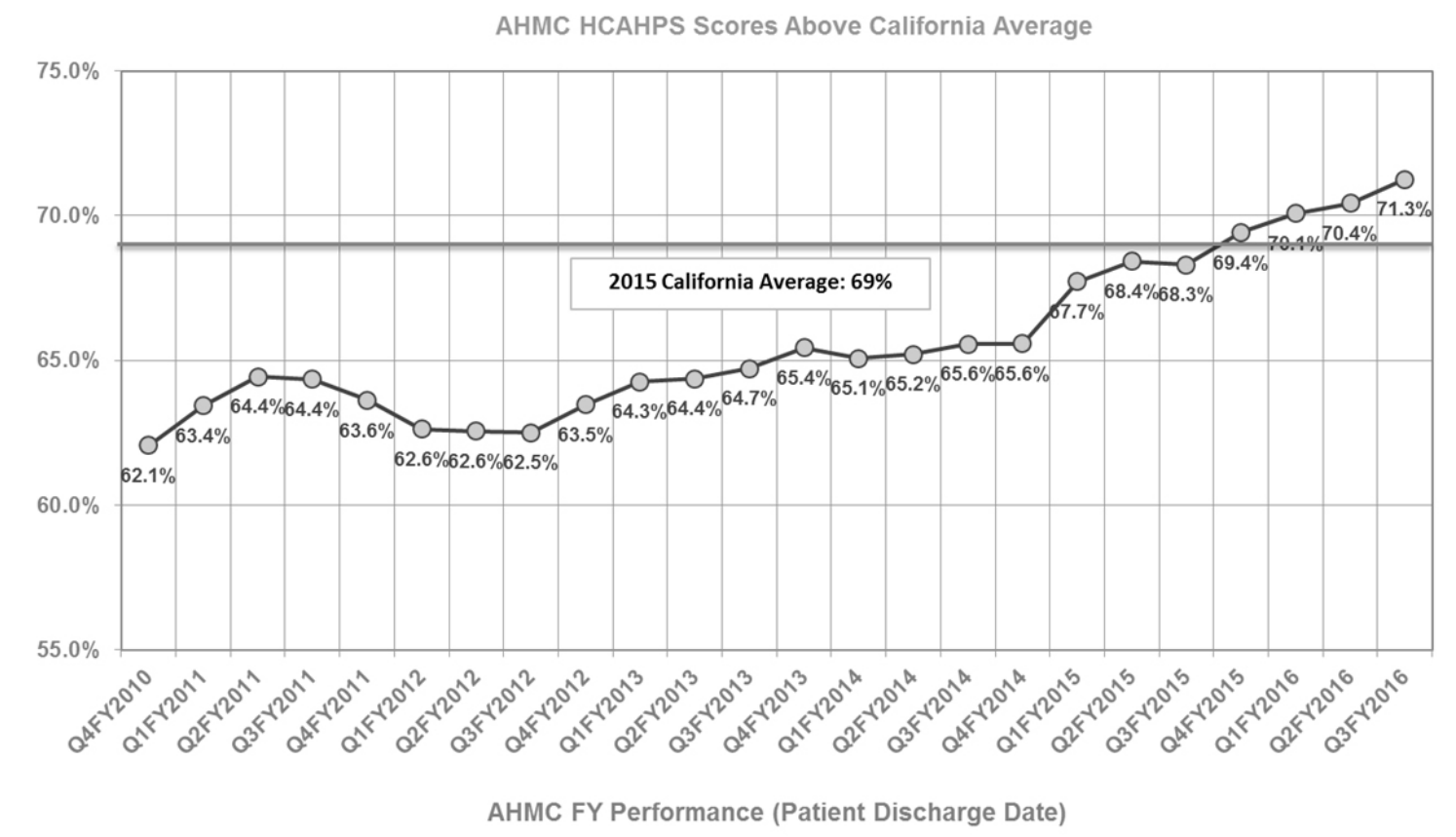

Figure 2. AHMC HCAHPS Achievements from 2010 to 2016: scores surpassing California hospital average performances

In collaboration with J.L. Morgan and Associates in 2014, AHMC hospitals implemented the Preventative Care Survey Program (PCSP), a follow-up survey conducted among patients post-discharge. In accordance with CMS regulations, follow-up calls are administered 24 to 48 hours postdischarge and prior to HCAHPS (see Figure 3). PCSP questions concentrate on transitional care from hospital to home, such as prescription filling, home medication use, doctor's follow-up appointments, and hospital follow-ups if necessary. As opposed to HCAHPS where surveyors are required to apply the CMS-approved script for each HCAHPS questionnaire, the PCSP allows patients to comment freely on each question. This factor of PCSP is especially beneficial to AHMC hospitals since all received comments allow us to assess specific behaviors and occurrences within the hospitals. Upon reviewing the comments for one of the facilities from 2015 , close to half of the comments were geared towards nurses. By further examining all nurse-related comments, the administrative team identified attitude and attentiveness as the most frequent complaint among nursing behaviors. Through this analysis, hospital administration teams and patient experience directors were able to strategize their patient experience improvement plans based on immediate discharge comments.

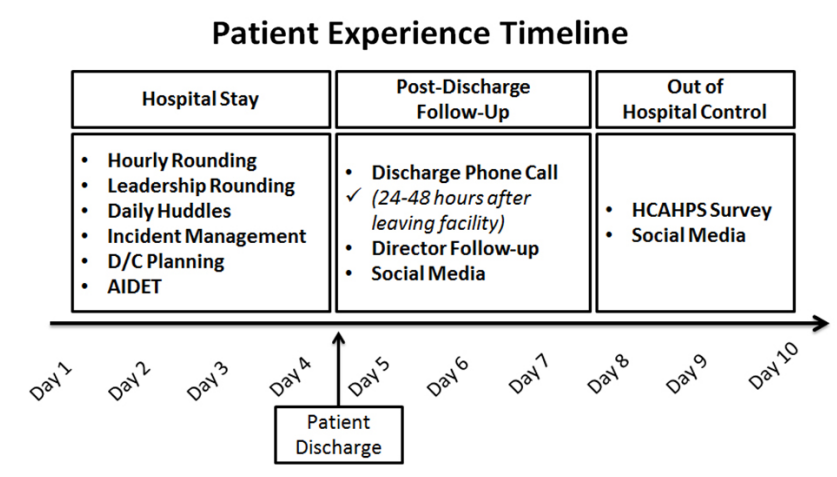

Figure 3. AHMC Patient Experience Timeline 
The healthcare system continues to advocate for patients and their families during their hospital stay by providing high quality of care. Through leadership and staff engagement in refining patient experience, AHMC's HCAHPS scores have risen above California hospital mean performance, and continues to achieve the goal of exceeding national average.

\subsection{Emergency Department}

Overcrowding in the ED has been a challenge across the U.S., and it has been worsening as the number of ED visits have increased ${ }^{[18-20]}$ In September 2015, AHMC hospitals applied Lean principles to reduce wait times and increase patient satisfaction.

Within healthcare settings, Lean is used as an operational improvement process that concentrates on continuous progression based on the voice of the patients. ${ }^{[18,21]}$ One of the key elements in Lean is to distinguish and eliminate waste. ${ }^{[18]}$ Waste generates additional costs and inefficiencies which burdens the delivery of high quality patient care.

During AHMC's Lean deployment, an interdepartmental team was established at each hospital. Teams consisted of an ED director, registration, nurses, physicians, administrators, and representatives from ancillary services. The Lean team carefully reviewed each step of the process and data to eliminate various waste. One of the most evident wastes encountered through patient observation was the redundancy of frequency in patient assessments. Triage nurses, ED nurses, and ED providers assessed patients multiple times with identical questions. As a solution, the process of patient assessment was standardized. The triage nurses have designated forms for patient assessment and handoff ensuring information flow between triage and treatment areas without repetitive interactions. Additional issues were also addressed with Lean tools, such as value-stream mapping, $5 \mathrm{~S}$, and kanban, to revise process flow and layout in the ED.
Five objectives were selected for the ED initiative:

(1) Door-to-doc time will be less than 30 minutes. Doorto-doc time measures the time between patient arrival and beginning of medical screening exam (MSE).

(2) Ancillary turnaround time will be less than 60 minutes. Ancillary turnaround time measures the time between ancillary service orders to patient disposition.

(3) Length of stay (LOS) will be less than 150 minutes. LOS captures the entire ED stay from arrival to discharge, transfer, or admission.

(4) Left without being seen (LWBS) will be less than $1 \%$ of total ED visits. LWBS refers to patients who left before MSE.

(5) EDPEC top box aggregate will be greater than $70 \%$. EDPEC currently includes the following categories: (1) registration process/arrival, (2) wait times, (3) ED nurses/staff communication, (4) ED physician/provider communication, (5) ancillary tests and treatments - lab and radiology, (6) communication regarding delays, (7) pain control, and (8) discharge information/home care.

System-wide ED data from July and November 2015 were compared to evaluate the effectiveness of AHMC's lean implementation (see Table 1). This report solely included discharged ED patients, and excluded patients with psychiatric conditions. A total of 13,982 and 13,737 ED visits were included from July and November, respectively. On average, the time required for a patient to see a physician/provider was reduced by $19.2 \%$ from 37 minutes in July to 30 minutes in November. Within the five-month period, ancillary turnaround times were reduced by 13 minutes from $96 \mathrm{~min}$ utes to 83 minutes. LOS was reduced from 194 minutes to 166 minutes (14.4\%). ED top aggregate gradually improved by $2.9 \%$ from July to November. The greatest improvement was observed in the percentage of LWBS from $1.6 \%$ to $0.4 \%$, which concluded with a $74.2 \%$ reduction.

Table 1. ED data July and November 2015

\begin{tabular}{|c|c|c|c|c|}
\hline & Goal & July (n =13,982) & November $(n=13,737)$ & \% Decreased \\
\hline Door-to-Doc Time (minutes) & 30 & 37 & 30 & 19.2 \\
\hline Ancillary Turnaround Time (minutes) & 60 & 96 & 83 & 14.1 \\
\hline Length of Stay (minutes) & 150 & 194 & 166 & 14.4 \\
\hline LWBS\% (of total visits) & $1 \%$ & $1.6 \%$ & $0.4 \%$ & 74.2 \\
\hline
\end{tabular}

The study demonstrated that process improvement tools, such as Lean, can emend ED quality and patient satisfaction through staff engagement. The success and sustainability of Lean projects were contingent upon understanding the current process and organizational infrastructure to rapidly adapt to change. By incorporating frontline staff into the Lean team, staff accountability and compliances were met from the beginning of the initiative. Resistance to change is inevitable, however, the Lean methodology facilitates initial momentum and builds sustainability through staff involve- 
ment.

\subsection{Employees}

AHMC utilizes a third party vendor for a comprehensive customer experience management program to conduct annual system-wide employee satisfaction survey. Based on the vendor's results, AHMC was able to assess employee satisfaction. According to the 2015 employee survey, AHMC has maintained a retention rate of $79 \%$ for the past two decades. $82 \%$ of employees were satisfied with the organization as a workplace, and $78 \%$ felt personal accomplishment. In order to affirm hospital employees' recognition with their work, AHMC consistently enables and challenges the front line staff at each facility to create and maintain an efficacious atmosphere.

Appropriate staffing and high job satisfaction are essential to achieve high quality patient outcomes. ${ }^{[22]}$ Furthermore, we have financed employee benefit programs such as employee health insurance, tuition reimbursement, and continuing medical education (CME) opportunities that have cultivated employee satisfaction. For instance, AHMC hosted an International Health Policy Symposium to ensure all administrators were timely informed of the current trends and development in American healthcare. Throughout the entire calendar year, AHMC hospitals offer complimentary exercise classes, nutrition presentations, health-aware menu options in the cafeterias, and weight-loss programs to the entire staff. Through a supportive and encouraging atmosphere of providing employee services, AHMC strives to sustain employee satisfaction for a better work environment. This state of action has proven to be significant in many circumstances to increase patient satisfaction. ${ }^{[22]}$

\subsection{Physician relations}

Relationships between physicians and hospitals are often perceived to lack clarity and precise communication. With the focus on better care coordination and cost reduction, the need for cooperation between hospitals and physicians have become increasingly necessary. ${ }^{[23]}$ Goal alignment and data sharing between the hospital and physician affect reimbursement benefits. ${ }^{[24]}$ AHMC Healthcare is committed to building meaningful relationships with local physicians and medical groups, which has led to refined quality of care and community integration.

One of AHMC's top priorities is to provide physicians with readily accessible facilities and equipment for services demanded by local communities. The number of available hospital beds continues to dwindle nationwide, and AHMC Healthcare addresses this issue by working closely with local medical groups and Independent Physicians Association
(IPA). ${ }^{[25]}$ Based on seasonal demands and data trends, the relationship between AHMC and local IPA's continue to help control the lack of bed availabilities. A unique aspect of AHMC's open model system is real-time network capabilities such as Health Insurance Portability and Accountability Act (HIPAA) compliant communication software and centralized bed availability dashboards. Another method implemented is the sharing of data analytics. When physicians treat high patient volume, difficulty in analyzing data trends within the same time period has been noted. ${ }^{[23]}$ The hospital's ability to decipher data trends helps maintain physician involvement. Through the exchange of data, AHMC Healthcare facilities, medical groups, and IPA's are provided with clear measures of performance and accountability. ${ }^{[24]}$

AHMC Healthcare reassures physician relationships through community integration events, such as health fairs, CME symposiums, and volunteer programs. Through communitydriven events, physicians and the community are able to educate themselves about current issues, trends, and preventative measures towards predictable epidemics, such as the seasonal flu. Established goal alignment between physicians and hospitals can significantly affect behavior and outcomes. ${ }^{[26]}$ By developing integration between physicians and hospitals within the community, AHMC Healthcare is establishing a more unified system which equates to better quality of care.

\subsection{Outpatient}

Outpatient service is a medical practice or test completed in a health facility without an overnight stay. As an open hospital system, patients who seek outpatient services are referred by physicians to AHMC. Therefore, hospital management must work closely with physicians to provide quality outpatient services. AHMC hospitals' current outpatient services include rehabilitation programs, radiological examinations, laboratory tests, and same day surgeries.

Starting in January 2016, the outpatient experience is measured by the Outpatient and Ambulatory Services Consumer Assessment of Health Providers and Systems (OAS CAHPS). The survey was created to inform the public of the quality of each facility in regards to communication of healthcare providers and staff, surgical preparation, and post-surgical care coordination. ${ }^{[27]}$ OAS CAHPS is an efficient evaluation tool for AHMC's current endeavors towards improving quality of care and patient experience within the outpatient setting.

In addition to the post-discharge survey, nurses follow-up with recently discharged inpatients by phone that are at highrisk of readmission, or those who may have difficulty adher- 
ing to discharge instructions. Patients will receive assistance on scheduling their outpatient follow-ups, continuing medication instructions, and reoccurring signs and symptoms for the illness.

While AHMC's outpatient services only accounts for $10 \%-35 \%$ of total patient volume, it may play a larger part of delivering healthcare services in other hospital systems. This is particularly salient in non-profit and international health settings. Internationally, physicians are often hired by the hospital, therefore outpatient services are a major component of hospital management. High quality of outpatient services enhance overall continuum care for patients, and leads to better health awareness for the community.

\subsection{Community}

AHMC Healthcare System and AHMC Health Foundation are committed to improving access to healthcare services for all members of our community with an emphasis on bridging cultural and linguistic barriers. AHMC Health Foundation, a non-profit organization formed in 2009 , exists to improve the quality of life for people in the communities served by AHMC hospitals. AHMC's community outreach program strives to broaden health services, increase frequency of educational events, and continue volunteer recruitment. Community outreach models have significantly reinforced health services utilization, satisfaction with health services, selfefficacy in navigating the healthcare system, services for at-risk populations, and hospital reputation. ${ }^{[28,29]}$

AHMC Healthcare System annually holds health fairs to provide health services within the communities. Volunteer staff and physicians provide free screenings to raise awareness of prevalent health issues such as cancer, diabetes, and cardiovascular diseases. Through the AHMC Healthcare Foundation, AHMC partners with local non-profit organizations and clinics to provide healthcare to underserved and uninsured individuals, such as the YMCA and Boys and Girls club.

On a monthly basis, Health Education departments at each AHMC facilities arrange an array of health education events on-site and off-site for the general public to attend. On an annual basis, over 700 educational programs are administered throughout all AHMC facilities. Many of these programs are conducted in multiple languages, such as Chinese and Spanish, to accommodate our multicultural population. Educational programs have focused on various topics, such as geriatric health, integration of East West Medicine, women's health, nutrition, and cancer awareness. One of our facilities had the opportunity to collaborate with the city government to organize a city-wide free tobacco cessation program

Published by Sciedu Press which included a five-week cessation class, individual counseling, and support group. Several AHMC facilities have been certified by United Nations Children's Emergency Fund (UNICEF) as baby friendly, and many have developed a comprehensive health education program on maternal, child health, and parenting classes.

AHMC facilities continue to strengthen their volunteer programs through partnerships with local schools and community centers. Our hospitals have organized a New Grad program which allows recently graduated nursing and allied health students an opportunity to gain more on-site exposure and clinical experience. We have established senior volunteer programs where senior volunteers can contribute their skills and experience to AHMC facilities and our patients.

The rise of social media usage has revolutionized the perspective of how medical facilities are viewed from a patient and public's perception. Identifying the most impactful strategy to properly approach each social media's inputs has quickly become a top priority. The widespread accessibility of social media sites such as Facebook and Yelp allows patients to immediately give their feedback of a facility and publicly share their opinions on these networks. Hospital administrators are often known to adapt a passive approach to social media commentaries due to fear of HIPAA violation and legal ramifications. By working closely with a legal team, many AHMC hospitals have developed innovative strategies to proactively engage the online communities by using tools such as blog posts and e-newsletters.

Community service is an essential component of the sixdimensional approach. Volunteers, service hours, educational programs, and online outreach have magnified the relationship the hospital has with the community.

\section{Discussion}

The six-dimensional approach has been proven to be beneficial with community hospitals as the forefront of the community's health. Increasing numbers of Americans are coping with chronic conditions ${ }^{[30,31]}$ where individuals are limited in receiving episodic care, and minimal assistance in disease management. This results in preventable ED visits and hospital readmission. ${ }^{[30,32]}$ There is an urgent demand for high quality and cohesive care for individuals living with chronic conditions, and are in need of certain coordination and accessibility assistance. ${ }^{[30,31]}$ A close partnership between hospitals, affiliated physician groups, and community organizations were formed to create a continuum of care from home, primary care settings, to hospital bedside. A renewed emphasis should be placed on applying a smooth transition upon patient's admittance and discharge period; for 
example, hospitals should act upon communication between ED and inpatient departments to expedite the admission process. Discharge planning and follow-up is an integral part of this transition to ensure that patients have received the appropriate education and care placement. With a more reinforced coordination throughout the patient's continuum of care, a seamless patient experience can be accomplished.

As quality and patient experience becomes more prominent, Lean methodology has become an applicable tool to reexamine a wide range of healthcare processes while emphasizing specific services that add value to patients. The Lean approach focuses on joining leadership and frontline staff in decision making to achieve sustainable improvement in quality and patient experience. As opposed to the traditional top-down management, Lean's shared responsibility mentality creates an engaging community for the entire staff to contribute. The adaptation of Lean methodology is pivotal in shaping the future of patient centered care based on the patients' and families' needs.

As healthcare shifts into the era of evidence-based practice, hospitals need to establish data infrastructures to enhance clinical, quality, and financial decisions. Hospitals should embrace technology as a new medium for communication with their patients. According to recent surveys, more than $70 \%$ of American adults use the Internet, and $64 \%$ of American adults own smart phones. ${ }^{[33,34]}$ This presents a substantial opportunity for hospitals to reshape the way healthcare staff communicates and delivers care through technology platforms, such as social media, cell phone applications, wearables, and web portals. As the impact of ACA becomes more prominent, hospitals should maintain their organizational flow and expand their care networks through the sixdimensional approach to bring patients and their families back to the center of their care.

\section{ACKNOWLedgements}

The authors would like to thank all facilities and staff involved with the research and writing of this document. The authors would also like to thank Michael Agron, David Allen, Allen Carpenter, Richard Castro, Eing-Min Chang, Kevin Chen, Phil Cohen, Steve Giordano, Paul Hensler, Iris Lai, Donald Lorack, Linda Marsh, Patrick Petre, Karen PriceGharzeddine, Stanley Toy, and the entire AHMC Healthcare System.

\section{REFERENCES}

[1] Kocher R, Emanuel EJ, DeParle NA. The Affordable Care Act and the future of clinical medicine: the opportunities and challenges. Annals of Internal Medicine. 2010; 153(8): 536-539. PMid: 20733178. http://dx.doi.org/10.7326/0003-4819-1 53-8-201010190-00274

[2] Aroh D, Colella J, Douglas C, et al. An Example of Translating Value-Based Purchasing Into Value-Based Care. Urologic Nursing. 2015; 35(2): 61-74. PMid: 26197624.

[3] Petrullo KA, Lamar S, Nwankwo-Otti O, et al. The Patient Satisfaction Survey: What does it mean to your bottom line? Journal of Hospital Administration, 2013, 2(2): 1-8.

[4] Centers for Medicare and Medicaid Services. Fiscal Year (FY) 2016 Results for the CMS Hospital Value-Based Purchasing Program. 2015 Fact Sheets Items [Retrieved 1/11, 2016].

[5] Boulding W, Glickman SW, Manary MP, et al. Relationship between patient satisfaction with inpatient care and hospital readmission within 30 days. The American journal of managed care. 2011; 17(1): 41-48. PMid: 21348567.

[6] Cathal D, Laura L, Derek B. A systematic review of evidence on the links between patient experience and clinical safety and effectiveness BMJ Open. 2013; 3(1): 57-60.

[7] Glickman SW, Boulding W, Manary M, et al. Patient satisfaction and its relationship with clinical quality and inpatient mortality in acute myocardial infarction. Circulation Cardiovascular Quality \& Outcomes. 2010; 3(2): 188-95. PMid: 20179265. http: //dx.doi.org/10.1161/CIRCOUTCOMES.109.900597

[8] Matthew PM, William B, Richard S, et al. The patient experience and health outcomes. New England Journal of Medicine. 2013; 368(3):
201-203. PMid: 23268647. http://dx.doi.org/10.1056/NEJ Mp1211775

[9] Zolnierek KB, Dimatteo MR. Physician communication and patient adherence to treatment: a meta-analysis. Medical care. 2009; 47(8): 826. PMid: 19584762. http://dx.doi.org/10.1097/MLR. Ob0 $13 \mathrm{e} 31819 \mathrm{a} 5 \mathrm{acc}$

[10] Centers for Medicare and Medicaid Services. The HCAHPS Survey - Frequently Asked Questions. HCAHPS: Patients' Perspectives of Care Survey. 2015. Available from: http://www.cms.gov/Medicare/Quality-Initiatives-P atient-Assessment-Instruments/HospitalQualityInit s/Downloads/HospitalHCAHPSFactSheet201007.pdf

[11] Ahmed N, Taylor K, McDaniel Y, et al. The role of an acute care for the elderly unit in achieving hospital quality indicators while caring for frail hospitalized elders. Population health management. 2012; 15(4): 236-240. PMid: 22731767. http://dx.doi.org/10.1089 /pop. 2011.0055

[12] Truven Health Analytics. 100 Top Hospitals Study, 2016, $23^{r d}$ Edition [Retrieved 2/29, 2016]. Available from: http://100tophosp itals.com/Portals/2/assets/100-Top-Study_web.pdf

[13] The Joint Commission. Congratulations to the 2013 Top Performer on Key Quality Measures Hospitals [Retrieved 3/1, 2016]. Available from: http://www.jointcommission.org/assets/1/6 /tp_state_list_2014.pdf

[14] The Joint Commission. America's Hospitals: Improving Quality and Safety [Retrieved 3/1, 2016]. Available from: http://www.jointcommission.org/assets/1/18/TJC_An nual_Report_2015_EMBARGOED_11_9_15.pdf 
[15] Blakley D, Kroth M, Gregson J. The impact of nurse rounding on patient satisfaction in a medical-surgical hospital unit. Medsurg Nursing. 2011; 20(6): 327. PMid: 22409118.

[16] Hutchings M, Ward P, Bloodworth K. 'Caring around the clock': a new approach to intentional rounding. Nursing Management, 2013; 20(5): 24-30. PMid: 23980790. http://dx.doi.org/10.7748/n $\mathrm{m} 2013.09 .20 .5 .24 . \mathrm{e} 1075$

[17] Tea C, Ellison MF. Proactive patient rounding to increase customer service and satisfaction on an orthopaedic unit. Orthopaedic Nursing. 2008; 27(4): 233-240. PMid: 18677250. http://dx . doi .org/10. 1097/01. NOR. 0000330305.45361.45

[18] Dickson EW, Anguelov Z, Vetterick D, et al. Use of lean in the emergency department: a case series of 4 hospitals. Annals of Emergency Medicine. 2009; 54(4): 504-510. PMid: 19423187. http: //dx.doi.org/10.1016/j.annemergmed.2009.03.024

[19] Trzeciak S, Rivers EP. Emergency department overcrowding in the United States: an emerging threat to patient safety and public health. Emergency medicine journal. 2003; 20(5): 402-405. PMid: 12954674. http://dx.doi.org/10.1136/emj.20.5.402

[20] Ungar L, O’Donnell J. Contrary to goals, ER visits rise under Obamacare. USA Today. 2015.

[21] Ng D, Vail G, Thomas S, et al. Applying the Lean principles of the Toyota Production System to reduce wait times in the emergency department. Canadian Journal of Emergency Medicine. 2010; 12(1): 50-7.

[22] Rosati RJ, Marren JM, Davin DM, et al. The Linkage between Employee and Patient Satisfaction in Home Healthcare. Journal for Healthcare Quality Official Publication of the National Association for Healthcare Quality. 2009; 31(2): 44-53. PMid: 19350879. http://dx.doi.org/10.1111/j.1945-1474.2009.00018.x

[23] Epstein J. Fostering Hospital-Physician Relationships: 5 strategies. 2014 [Retrieved 12/17, 2015]. Available from: http://managedhealthcareexecutive.modernmedicine. com/managed-healthcare-executive/news/fostering-h ospital-physician-relationships-5-strategies

[24] Jacobson R. 5 Questions for Building Physician Engagement. 2012 [Retrieved 12/17, 2015]. Available from: http://www. beckershospitalreview.com/hospital-p hysician-relationships/5-questions-for-building-p hysician-engagement.html

[25] Vesely R. California sees decline in number of hospital beds: report 2010 [Retrieved 12/18, 2015]. Available from: http: //www.mode rnhealthcare.com/article/20100502/NEWS/305029989

[26] Weatherly J, Nyquist S. Strengthening the Physician-Hospital Relationship: 10 Keys to Success. 2008 [Retrieved 12/24, 2015] Available from: http://healthleadersmedia.com/content /LED-222148/Strengthening-the-PhysicianHospital-R elationship-10-Keys-to-Success.html-\#

[27] JL Morgan and Associates. Outpatient and Ambulatory Services CAHPS (OAS CAHPS). Our Services. 2015 [Retrieved 12/29, 2015].

[28] Tataw DB, Bazargan-Hejazi S, James FW. Health services utilization, satisfaction, and attachment to a regular source of care among participants in an urban health provider alliance. Journal of Health \& Human Services Administration. 2011; 34(1): 109-41. PMid: 21847878.

[29] Tuazon NC. Community outreach: moving beyond hospital walls. Nursing management. 2010; 41(5): 32-36. PMid: 20418750. http: //dx.doi.org/10.1097/01. NUMA.0000372031.44982.99

[30] Shugarman L, Whitenhill K. The Affordable Care Act Proposes New Provisions to Build a Stronger Continuum of Care. Generations. 2011; 35(1): 11-18.

[31] Houdt S V, Heyrman J, Vanhaecht K, et al. Care pathways across the primary-hospital care continuum: using the multi-level framework in explaining care coordination. Bmc Health Services Research. 2013; 13(3): 296. PMid: 23919518. http: //dx.doi.org/10.1186/147 2-6963-13-296

[32] Collins R. Introduction: seamless communication across the continuum of care. Health management technology. 2014; 35(9): 23. PMid: 25265673

[33] Pew Research Center. Broadband Technology Fact Sheet. Fact Sheet. 2013 [Retrieved 12/20, 2015]. Available from: http://www.pewinternet.org/fact-sheets/broadband-t echnology-fact-sheet/

[34] Pew Research Center. U.S. Smartphone Use in 2015. Internet \& Tech. 2015 [Retrieved 12/11, 2015]. Available from: http://www.pewi nternet .org/2015/04/01/us-smartphone-use-in-2015/ 